\title{
85617 - PERCEPÇÃO DOS ENFERMEIROS ACERCA DA AVALIAÇÃO MULTIDIMENSIONAL DO IDOSO NA ATENÇÃO PRIMÁRIA À SAÚDE
}

\section{Apresentação Oral - Gerontologia}

\author{
Juliete Coelho Gelsleuchter / GELSLEUCHTER, J.C. / Universidade Federal de Santa Catarina; \\ Karina Silveira de Almeida Hammerschmidt / HAMMERSCHMIDT, K. S. A. / Universidade Federal de Santa \\ Catarina; Juliana Balbinot Reis Girondi / GIRONDI, J. B. R / Universidade Federal de Santa Catarina; \\ Laura Cavalcanti de Farias Brehmer / BREHMER, L. C. F / Universidade Federal de Santa Catarina; \\ Melissa Orlandi Honório Locks / HONORIO, M. O / Universidade Federal de Santa Catarina; \\ Anderson Abreu de Carvalho / CARVALHO, A. A / Universidade Federal de Santa Catarina
}

Introdução: Avaliação multidimensional da pessoa idosa (AM) é uma forma de avaliar os aspectos gerais de saúde e sociais da pessoa idosa. Pode ser usada por qualquer profissional da saúde desde que capacitado ${ }^{1}$. Objetivo: Identificar a percepção dos enfermeiros sobre AM do idoso na Atenção Primeira à Saúde. Metodologia: Trata-se de estudo de caso holístico, de casos múltiplos. Participaram do estudo cinco enfermeiros de uma Unidade Básica de Saúde de São José/SC, no período de dezembro de 2016. A coleta de dados buscou evidências através de entrevista semi-estruturada. Cada entrevista gerou um relatório e por fim relatório final cruzando todos os dados ${ }^{2}$. Os aspectos desta pesquisa estão de acordo com a resolução 466/12 e aprovada no Comitê de ética sob parecer 1.833.375. Resultados: O uso da AM pelos enfermeiros não foi unanimidade, a maior justifica para o não uso foi a falta de tempo e pouco domínio para trabalhar com idosos. Como fortalezas da AM mencionam identificação de pontos não só da enfermagem, maior conhecimento e controle do quadro clínico do paciente possibilitando diagnóstico real e preciso. Conclusões: Estudos apontam que o tempo médio despendido para aplicar AM foi de 11 minutos, contrapondo a fala dos participantes relacionado a falta de tempo, tendo em vista que é uma avaliação relativamente rápida. Outra questão foi o despreparo de alguns profissionais em avaliar a pessoa idosa evidenciado e importância dos cursos de graduação em enfermagem em reforçar os conteúdos de geriatria e gerontologia. Lembrando que, as universidades têm papel importante na formação, mas também cabe a responsabilidade do profissional pela busca constante de capacitação e atualização. Nesse contexto a educação permanente pode ser uma forma de ajudar esses profissionais aprimorar seus conhecimentos. Deste modo a AM possibilita o levantamento de dados de todas as dimensões do idoso, que possibilita condutas de prevenção, orientação e encaminhamentos, tudo com objetivo de melhorar a qualidade de vida dos idosos procurando manter suas funções por maior período de tempo.

Palavras-chave: Idoso; Enfermagem; Atenção primaria à Saúde.

Referências: 1. BRASIL. Ministério da Saúde. Secretaria de Atenção à Saúde. Departamento de Atenção Básica. Envelhecimento e saúde da pessoa idosa / Ministério da Saúde, 2006. 192 p. il. (Cadernos de Atenção Básica, n. 19). 2. YIN, Robert. Estudo de Caso: Planejamento e Métodos. 3. ed. Porto Alegre: Bookman, 2005. 212 p. 